\title{
Opioid Peptides: Potential for Drug Development
}

\author{
Jane V. Aldrich ${ }^{1,{ }^{*}}$ and Jay P. McLaughlin ${ }^{2}$ \\ ${ }^{1}$ Department of Medicinal Chemistry, The University of Kansas, Lawrence, KS 66045 \\ ${ }^{2}$ Torrey Pines Institute for Molecular Studies, Port St. Lucie, FL 34987
}

\begin{abstract}
Opioid receptors are important targets for the treatment of pain and potentially for other disease states (e.g. mood disorders and drug abuse) as well. Significant recent advances have been made in identifying opioid peptide analogs that exhibit promising in vivo activity for treatment of these maladies. This review focuses on the development and evaluation of opioid peptide analogs demonstrating activity after systemic administration, and recent clinical evaluations of opioid peptides for possible therapeutic use.
\end{abstract}

\section{Introduction}

The endogenous ligands for opioid receptors are peptides. Since their initial discovery in the 1970s, there have been extensive studies of the structure-activity relationships (SAR) of opioid peptides for each of the opioid receptors (see refs. [1, 2] for reviews). However, the evaluation of opioid peptide analogs in vivo has been limited, typically to examination of activity following central (intrathecal, i.t., or intracerebroventricular, i.c.v.) administration. Relatively few opioid peptide analogs have been evaluated following more clinically relevant systemic (e.g., by subcutaneous, s.c., or oral, p.o.) routes of administration. This review focuses on reports of the analgesic and other behavioral effects of opioid peptides in animals following systemic administration, structural modifications that enhance the systemic activity of opioid peptide analogs, and also recent clinical trials of opioid peptides. The reader is referred to other recent reviews [2-5] for more detailed discussions on the development of these and other opioid peptides.

\section{Development of systemically active opioid peptides}

Given the importance of mu opioid receptor (MOR) agonists such as morphine as analgesics, the primary focus for opioid peptide analog development has been for the treatment of pain, although a few opioid peptides have been examined for other applications (see Table 1 and below). The emphasis in the majority of cases has been to induce analgesia through activation of opioid receptors in the central nervous system (CNS), although peripheral opioid receptor activation, particularly of kappa opioid receptors (KOR) [6], can also mediate analgesic activity (see below). In order to develop opioid peptide analogs as potential drugs they must be active after dosing by a clinically relevant route, typically by a form of systemic administration. There has been interest in examining opioid peptide

\footnotetext{
(C) 2011 Elsevier Ltd. All rights reserved.

"Corresponding author: Jane V. Aldrich, Ph.D., Department of Medicinal Chemistry, 1251 Wescoe Hall Dr., 4050 Malott Hall, The University of Kansas, Lawrence, KS 66045, Phone: (785) 864-2287, Fax: (785) 864-5326, jaldrich@ku.edu.

Publisher's Disclaimer: This is a PDF file of an unedited manuscript that has been accepted for publication. As a service to our customers we are providing this early version of the manuscript. The manuscript will undergo copyediting, typesetting, and review of the resulting proof before it is published in its final citable form. Please note that during the production process errors may be discovered which could affect the content, and all legal disclaimers that apply to the journal pertain.
} 
analogs for systemic, including oral, activity in antinociceptive assays in animals for more than 20 years [7], with a number of peptides identified recently with improved pharmacokinetic properties. This review discusses these advancements in recent years in the search for opioid peptide analogs that are active after systemic administration.

\section{Opioid peptides exhibiting activity after systemic administration in animals}

An early successful demonstration of opioid peptides that exhibited activity after systemic administration were analogs of dermorphin (Figure 1), an endogenous opioid peptide obtained from amphibian skin that exhibits high selectivity for MOR. An early report [7] described analogs of the $\mathrm{N}$-terminal tetrapeptide, which appears to be the minimum sequence from dermorphin required for agonist activity, that contained D-Arg at position 2 and that exhibited antinociceptive activity after both s.c. and oral administration. More recently, the dermorphin tetrapeptide analog ADAMB (Figure 1) was designed by incorporating modifications, including $\mathrm{N}$-terminal quanidylation, from several dermorphin tetrapeptides that exhibited weak oral analgesic activity. ADAMB was 4- and 38-fold more potent as an analgesic than morphine following oral and s.c. administration, respectively (see Table 2), and lasted more than twice as long [8]. While the peptide was reasonably potent after oral administration $\left(\mathrm{ED}_{50}=5.8 \mathrm{mg} / \mathrm{kg}\right.$ in mice), its potency by this route was 65 -fold lower than observed after s.c. administration, suggesting relatively low bioavailability by the oral route.

The best studied of the tetrapeptide analogs containing D-Arg ${ }^{2}$ is Dmt-DALDA (Dmt-DArg-Phe-LysNH ${ }_{2}, \mathrm{Dmt}=2^{\prime}, 6^{\prime}$-dimethyltyrosine; see ref. [4] for a review). This peptide is much more potent and demonstrates longer lasting analgesic activity than morphine when administered subcutaneously. Tolerance developed to this peptide's analgesic activity, but interestingly it exhibited minimal cross tolerance in morphine-tolerant mice. Dmt-DALDA is transported across Caco-2 monolayers, a model of the intestinal barrier, suggesting that this peptide could be orally absorbed. Since blockade of delta opioid receptors (DOR) can reduce morphine tolerance [4], Dmt-DALDA was linked to the DOR antagonist TICP[ $\Psi$ ] (Tyr-Tic $\Psi\left[\mathrm{CH}_{2} \mathrm{HN}\right] \mathrm{Cha}$-Phe, Tic = 1,2,3,4-tetrahydroisoquinoline-3-carboxylic acid, $\mathrm{Cha}=$ cyclohexylalanine) via an ethylenediamine linker at the $\mathrm{C}$-termini in an effort to develop a MOR agonist/DOR antagonist producing minimal tolerance and which can cross the bloodbrain barrier (BBB). The resulting peptide exhibited analgesic activity following s.c. administration comparable to morphine (Table 2), but with a longer duration of activity and substantially less tolerance [4].

Notably, recent reports suggest these opioid peptides containing D- $\mathrm{Arg}^{2}$ have an unusual pharmacological profile that involves the release of endogenous opioid peptides, particularly the endogenous KOR ligands the dynorphins. This could possibly result in a more favorable side effect profile by minimizing liabilities such as respiratory depression and dependence associated with traditional opioid analgesics (see ref. [9] for a review).

Structural modifications similar to those used in ADAMB, including N-terminal guanidinylation, have been made to the MOR-selective endogenous mammalian opioid peptide endomorphin-1 to enhance BBB penetration (see Figure 1) [10]. The four analogs that contained D-Ala ${ }^{2}$ along with guanidindo-Tyr-D-Pro-Gly-Trp-Phe $(p-\mathrm{Cl}) \mathrm{NH}_{2}$ each exhibited modest antinociception after systemic administration (see Table 2) which was blocked by naloxone administered i.c.v. but not by the peripherally-restricted antagonist naloxone methiodide, suggesting that these peptides produced their effects through MOR in the CNS.

The Dmt-Tic pharmacophore has been the basis of extensive SAR studies for opioid receptor interaction, particularly for DOR [11]. The DOR system is associated with the 
regulation of emotional states (e.g., depression and anxiety), and although nonpeptide DOR agonists have shown antidepressant and anxiolytic activity, they also produce convulsions [12]. The peptidomimetic Dmt-Tic derivative UFP-512 (Figure 1) is a DOR selective agonist that has been examined in vivo [13-15]. UFP-512, but not the DOR agonist DmtTic-NHCH 2 -Bid (UFP-502, Bid = 1H-benzimidazole), exhibited antidepressant-like activity in the forced swimming test (Table 2) [14], suggesting that the $\mathrm{CH}_{2} \mathrm{CO}_{2} \mathrm{H}$ functionality conferred favorable pharmacokinetic properties, facilitating peptide transport across the BBB. Notably, tolerance did not develop to the antidepressant-like activity in this assay after 7 days of chronic treatment [13]. This compound also exhibited anxiolytic activity in two models following intraperitoneal (i.p.) administration [14]. Further studies of this peptidomimetic in a rat model of Parkinson's disease indicate a complex mechanism of action, with lower doses facilitating locomotor activity while higher doses worsened Parkinsonism-like symptoms, suggesting UFP-512 behaved as a partial agonist [15].

In contrast, the Dmt-Tic derivative Dmt-Tic-Lys- $\mathrm{CH}_{2}-\mathrm{Ph}(\mathrm{MZ}-2)$ is an antagonist at both MOR and DOR, blocking centrally administered morphine after both s.c. and oral administration [16]; after oral administration it was approximately 4-fold less potent than naloxone at antagonizing morphine in the hot plate test (Table 2). When MZ-2 was administered daily at a low dose $(0.01 \mathrm{mg} / \mathrm{kg}$ s.c. $)$ that did not prevent morphine- or DOR agonist-induced antinociception, it prevented the development of tolerance to morphine, consistent with its antagonist activity at DOR. Subsequently it was shown that oral administration of this peptidomimetic ( $10 \mathrm{mg} / \mathrm{kg} / \mathrm{day})$ could also reduce weight gain and improve other obesity-related factors in obese mice [17].

Recently there has been an interest in bi- and multifunctional opioid peptide ligands with activity at more than one target (see ref. [4] for a review). One approach has been to develop peptides possessing both opioid agonist and neurokinin 1 antagonist activities, since a neurokinin 1 antagonist was shown to attenuate the development of morphine tolerance (see ref. [4]). One of these peptides, TY005, has recently been evaluated in vivo for antinociceptive activity against nerve injury-induced hypersensitivity (i.e. antihyperalgesia) following i.v. administration [18]. It was found to be more effective than morphine in this model and did not lead to the development of analgesic tolerance.

Derivatives of the KOR endogenous opioid peptide dynorphin A have also been examined for analgesic activity following systemic administration. The dynorphin A fragment dynorphin A-(1-13) has been shown to exhibit antinociception in primates and humans in addition to in rodents (see ref. [3] for a review). The dynorphin A-(1-8) analog E2078 has been the most extensively studied in animals, and has also been administered to humans as an analgesic (see ref. [3] for a review). A dynorphin A-(1-7) analog stabilized to metabolism, SK-9709 (Figure 1), also exhibited antinociceptive activity following systemic (s.c.) administration (Table 2) [19]. In addition, YFa, designed as a chimeric peptide between Met $^{5}$-enkephalin-Arg ${ }^{6}-\mathrm{Phe}^{7}$ and FMRFa (Phe-Met-Arg-Phe amide) with structural similarities to dynorphin A, produced KOR-mediated antinociception in rats following i.p administration without producing tolerance [20], although large doses ( $\geq 40 \mathrm{mg} / \mathrm{kg}$ ) were required. Structural modifications, i.e. D-Ala ${ }^{2}$ and/or $\mathrm{Phe}(p-\mathrm{Cl})^{4}$ incorporated into $\mathrm{YFa}$ to enhance metabolic stability and improve BBB penetration, resulted in enhanced analgesic potency following i.p. administration (see Table 2), but altered the opioid receptor selectivity [21, 22]. Like the parent peptide, these analogs did not produce antinociceptive tolerance. [NMeTyr ${ }^{1}$ ]dynorphin A-(1-13) and its C-terminal amide derivative have been shown to enhance morphine-induced antinociception in morphine-tolerant rats after systemic administration [23]. Interestingly, although the compounds were not active after s.c. administration, they were active following pulmonary delivery. 
While the primary emphasis in the in vivo evaluation of opioid peptides has been for their antinociceptive activity, opioid peptide analogs have other potential therapeutic applications (see Box 1). We have recently demonstrated that the dynorphin A analog zyklophin (Figure 1), which is a highly KOR selective antagonist containing modifications that stabilize it to metabolism, is not only active after systemic (s.c.) administration but can also antagonize KOR in the CNS for a finite duration [24]. This peptide could have advantages over nonpeptide KOR-selective antagonists, which exhibit unusually prolonged antagonist activity (weeks after a single dose) [3]. Zyklophin also blocked drug seeking behavior in a model of stress-induced reinstatement of cocaine abuse, suggesting that such KOR peptide antagonists could have potential therapeutic applications in the treatment of drug abuse.

\section{Box 1}

\section{Outstanding issues in the development of opioid peptides as therapeutic} agents

1. Delivery of peptide therapeutics and increasing bioavailability

The limited bioavailability of most peptides following oral administration has limited the development of opioid peptides as therapeutic agents. The demonstration of oral activity at reasonable doses for some opioid peptides suggests the possibility in selected cases to develop orally active opioid peptides, but it will be necessary to explore other routes of administration for a number of therapeutically relevant peptides. The demonstrated activity of dynorphin analogs following inhalation [23] suggest that it may be possible to administer these peptides by other methods not involving injection that could increase acceptance of such therapeutic agents.

2. Potential effects of species differences on blood-brain barrier permeability

The recent results for the central vs. peripheral activity of MMP-2200 in mice vs. rhesus monkeys [27.28] illustrates one of the challenges in developing centrally acting peptides. Because of their polar nature, peptides often cross biological membranes by mechanisms other than passive diffusion, including via specific transporters (see ref. [25]). Thus species differences could have a greater impact on the distribution of peptides than for more hydrophobic small molecules that penetrate the CNS by passive diffusion. Understanding species differences in blood-brain barrier transport will also be important in the development of opioid peptide ligands restricted to the periphery.

3. Side effect profiles of opioid peptides compared to corresponding nonpeptide opioid ligands

Side effects, e.g. the convulsant activity of small molecule DOR agonists, have limited the therapeutic development of some nonpeptide opioid ligands. In some cases distinct differences have been demonstrated for opioid peptide ligands compared to their nonpeptide counterparts, suggesting peptide opioid ligands could exhibit different side effect profiles from small molecule ligands. The high specificity of peptide ligands for opioid receptors can minimize off-target side effects compared to small molecule ligands, and therefore additional advantages of opioid peptide vs. nonpeptide ligands in terms of side effect profiles could emerge as more in vivo results are reported. 


\section{Chemical strategies to increase CNS penetration and stability of opioid peptides}

Different approaches, including cationization (e.g. ADAMB), glycosylation and pegylation, have been used to enhance the ability of opioid peptide analogs to penetrate the BBB along with increasing their stability (see ref. [25] for a review). Glycosylation has been suggested to enhance the potency of systemically administered peptides and to promote their penetration across the BBB. Glycosylation of opioid peptides was initially reported over 20 years ago, and since then a variety of glycosylated opioid peptides have been synthesized and examined for opioid activity (see ref. [26]). Recent results with glycosylated opioid peptides, however, suggest that the effects of glycosylation on BBB penetration may be species dependent. The Leu-enkephalin analog MMP-2200, which is a MOR/DOR agonist that contains the disaccharide lactose attached to the side chain of serine at the C-terminus (see Figure 1), produces antinociception activity in mice that is not blocked by the peripherally-restricted opioid antagonist naloxone methiodide, verifying the involvement of central opioid receptors in the antinociceptive activity in this species [27]; MMP-2200 also exhibited less tolerance and less severe withdrawal symptoms compared to morphine. In rhesus monkeys, however, this glycopeptide appears to act as a peripheral MOR/DOR agonist with limited penetration into the CNS [28].

Pegylation has also been explored to enhance the analgesic potency of opioid peptides. In the case of the DOR selective agonist cyclo[D-Pen ${ }^{2}$,D-Pen ${ }^{5}$ enkephalin (DPDPE), which is cleared primarily by biliary excretion, $\mathrm{N}$-terminal pegylation decreases hepatic clearance and enhances analgesia following i.v. administration. This pegylated derivative appears to function as a prodrug, undergoing hydrolysis to the parent peptide [29]. Attachment of 2 $\mathrm{kDa}$ poly(ethyleneglycol) (PEG) to the N-termini of the dimeric enkephalin analog biphalin (Figure 1) enhanced antinociceptive activity somewhat following all routes of administration examined (i.c.v., i.v., intramuscular, i.m., and s.c.; see Table 2) [30].

Recently, novel head-to-tail cyclic peptides have been reported that exhibit opioid activity. [YpwFG], a cyclized derivative of endomorphin- 1 containing a glycine bridge between $\mathrm{Tyr}^{1}$ and Phe ${ }^{4}$ (Figure 1) synthesized to enhance membrane permeability, exhibits antinociceptive activity in mice following i.p. administration [31]. As expected, cyclization stabilizes the peptide to metabolic degradation by proteases. Studies with the peripherally restricted antagonist naloxone methiodide suggest that at lower doses the peptide produces antinociception predominantly through peripheral MOR, and only at a higher dose $(20 \mathrm{mg} /$ kg i.p.) does the peptide activate MOR in the CNS. In our laboratory we synthesized the natural product cyclic tetrapeptide CJ-15,208 (cyclo[Phe-D-Pro-Phe-Trp]) [32] and found that it exhibits potent antinociceptive activity in vivo in the $55^{\circ}$ warm water tail withdrawal assay in mice after either central (i.c.v.) (Ross, et al., submitted) or peripheral (i.p.) administration.

Novel opioid peptides with sequences unrelated to the endogenous opioid peptides have also been evaluated in animals (Table 2), and two analogs have undergone clinical trials (see below). An all D tetrapeptide (D-Phe-D-Phe-D-Nle-D-ArgNH $\mathrm{N}_{2}$ ), identified from a combinatorial library, exhibits exceptional selectivity for KOR in vitro and appears to be restricted primarily to the periphery after parental administration [33]. Because of the D stereochemistry this peptide should be resistant to metabolism by proteases. Further structural modification resulted in FE 200665 (now known as CR665) and a second analog FE200666 that exhibit exceptional separation of antinociceptive activity from centrally mediated side effects (e.g. sedation) [34]. CR665 and a third generation peptide CR845 have been evaluated in clinical trials (see below). 


\section{Opioid peptides examined in humans}

Examination of dynorphin fragments and analogs in humans was initiated in the 1980's and 1990's when dynorphin A-(1-13) was evaluated for the treatment of severe pain and suppression of opioid withdrawal symptoms following i.v. and i.t. delivery (see ref. [3] for a review). The Dyn A-(1-8) analog E-2078 given intramuscularly was also evaluated in humans and shown to have analgesic activity comparable to the clinically used small molecule narcotic analgesic pentazocine in surgical patients (see ref. [3]). Recently, a novel dynorphin A-(1-13) derivative CJC-1008, containing a maleimidopropionyl group to promote its covalent attachment to serum albumin and to extend its duration of action, was examined following i.v. infusion in a phase II clinical trial in postherpetic neuralgia patients [35], and found to exhibit analgesic activity for at least 8 , but for less than 24 , hours.

As noted above, two all D tetrapeptide peripherally selective KOR agonists have undergone clinical trials. CR665 (0.36 mg/kg i.v.) was evaluated in a double blind study on experimental pain involving skin, muscle and viscera, and found to have a selective analgesic effect on visceral pain, consistent with its peripheral KOR selective activity, in contrast to the clinically used narcotic analgesic oxycodone which had a generalized effect on all three types of pain [36]. A third generation analog CR845 has completed a Phase IIa proof-of-concept clinical trial after a single i.v. infusion $(0.040 \mathrm{mg} / \mathrm{kg})$ to women following laparoscopic hysterectomy (NCT00877799, http://clinicaltrials.gov) with positive results reported in terms of pain relief and decrease in the incidence of undesirable side effects (Cara Therapeutics press release, February 8, 2010, http://www.caratherapeutics.com/pressreleases.php).

In addition to the application of opioid peptides for the treatment of severe pain, the endogenous opioid peptide $\mathrm{Met}^{5}$-enkephalin (referred to as opioid growth factor, OGF) has been examined in Phase I and II clinical trials for the treatment of advanced pancreatic cancer [37], based on its reported interaction with a target (the OGF receptor) that is distinct from the classic opioid receptors and its inhibition of pancreatic cancer in cell culture and in nude mice. This peptide $(0.25 \mathrm{mg} / \mathrm{kg}$ i.v.) was reported to provide clinical benefit to $53 \%$ of the patients who had failed standard chemotherapy, with a 3-fold increase in survival time. Its efficacy is presently being examined against other cancers (Phase II clinical trials in head and neck cancers, and Phase I clinical trial in hepatocellular cancer; http://clinicaltrials.gov, see Table 2).

A novel approach to treat intractable pain that deserves mention is gene therapy with vectors inducing expression of an endogenous opioid peptide. Replication defective herpes simplex virus-based vectors have been used to express human proenkephalin and an engineered endomorphin-2 gene in animal models, and have been shown to be particularly effective in models of inflammatory and cancer pain. The results of the first small clinical trial with the vector NP2 expressing proenkephalin have just been reported [38], and provided promising results in terms of safety and pain relief.

\section{Conclusions}

Peptides have several advantages as potential drugs, including high activity, high specificity, low toxicity, and minimization of drug-drug interactions [39]. However, challenges remain in developing opioid peptides as potential therapeutic agents, particularly in terms of their activity after systemic administration and their ability to cross the BBB (see Box 1). Stabilizing these peptides to metabolism sufficiently to permit systemic administration can be accomplished through a variety of structural modifications (see Figure 1) while still retaining the desired pharmacological activity. The metabolic stability of the peptides can be fine-tuned by the choice and number of modifications introduced. Often multiple 
modifications are necessary to produce significant activity following systemic administration, as was the case with many of the peptides discussed here. However, other factors in addition to metabolism, e.g. biliary excretion, can also limit the systemic bioavailability of opioid peptide analogs.

A significant challenge in the development of opioid peptides for clinical use is optimizing their distribution (or lack thereof) into the CNS (see Box 1). As described above, both peptides that can cross the BBB (e.g. Dmt-DALDA and zyklophin) as well as peptides that appear to be restricted to the periphery (e.g. CR665 and CR845) have been identified. The mechanism of action and therapeutic application determines whether it will be necessary for a drug to cross the BBB, or whether activity in the periphery is sufficient and indeed advantageous. For the treatment of pain, agonists that are restricted to the periphery can have distinct advantages because they should not exhibit centrally mediated undesirable side effects (e.g. addiction) that severely limit the clinical use of existing therapeutics. In contrast, for treatment of mood disorders and substance abuse, demonstration that the opioid peptide analogs can cross the BBB is important for the development of these compounds as potential therapeutic agents.

Multiple mechanisms have been implicated in the BBB penetration of opioid peptide analogs [25]. Enhancing peptide lipophilicity can enhance BBB penetration by passive diffusion [25], and the CNS penetration of several MOR selective peptides with different structures was recently correlated with their lipophilicity [40]. However, other mechanisms can be involved in transporting peptides across the BBB (see ref. [25]) or in limiting their CNS penetration (i.e. efflux proteins such as P-glycoprotein [29]). Modifications such as glycosylation or an N-terminal guanidyl group that enhance the hydrophilicity of peptides have also been explored to increase BBB penetration. Unfortunately information on the CNS penetration of opioid peptides is fragmentary and the evaluations performed used a variety of different methods (see ref. [40]), making comparisons difficult and rational design of CNS active peptides challenging. Moreover, apparent species differences in CNS penetration of some peptides (see above, also Box 1) further complicates development of CNS active peptides.

Delivery of therapeutic peptides remains a challenge (see Box 1), but recent advances, e.g. in structural modification strategies, pulmonary delivery [23] and demonstrated activity following oral administration, hold promise that opioid peptides can be systemically administered by a variety of methods including those that don't involve injection to yield therapeutic benefit.

\section{Acknowledgments}

JVA is funded by NIH/NIDA grants DA018832 and DA023924, and JPM is funded by NIH/NIDA grant DA023924 and funds from the State of Florida, Executive Office of the Governor's Office of Tourism, Trade and Economic Development.

\section{Abbreviations}

Abbreviations for amino acids follow IUPAC-IUB Joint Commission of Biochemical Nomenclature (Eur. J. Biochem. (1984) 138, 9 37). Other abbreviations are

$\begin{array}{ll}\text { BBB } & \text { blood-brain barrier } \\ \text { Cha } & \text { cyclohexylalanine } \\ \text { CNS } & \text { central nervous system }\end{array}$




$\begin{array}{ll}\text { Dap } & 2,3 \text {-diaminoproprionic acid } \\ \text { Dmt } & 2^{\prime}, 6^{\prime} \text {-dimethyltyrosine } \\ \text { DOR } & \text { delta opioid receptor } \\ \text { DPDPE } & \left.\text { cyclo[D-Pen }{ }^{2} \text { Pen }^{5}\right] \text { enkephalin } \\ \text { i.c.v } & \text { intracerebroventricular } \\ \text { i.m } & \text { intramuscular } \\ \text { i.t } & \text { intrathecal } \\ \text { i.v } & \text { intravenous } \\ \text { KOR } & \text { kappa opioid receptor } \\ \text { MOR } & \text { mu opioid receptor } \\ \text { Pen } & \text { penicillamine } \\ \text { p.o } & \text { per oral } \\ \text { s.c } & \text { subcutaneous } \\ \text { SAR } & \text { structure-activity relationships } \\ \text { Tic } & 1,2,3,4-\text { tetrahydroisoquinoline-3-carboxylic acid }\end{array}$

\section{References}

1. Aldrich, JV.; Vigil-Cruz, SC. Narcotic analgesics. In: Abraham, DJ., editor. Burger's Medicinal Chemistry \& Drug Discovery. 6. Vol. 6. John Wiley \& Sons, Inc; 2003. p. 329-481.

2. Aldrich, JV. Opioid peptides. In: Howl, J.; Jones, S., editors. Bioactive Peptides. CRC Press; 2009. p. 103-136.

3. Aldrich JV, McLaughlin JP. Peptide kappa opioid receptor ligands: Potential for drug development. AAPS J. 2009; 11:312-322. [PubMed: 19430912]

4. Schiller PW. Bi- or multifunctional opioid peptide drugs. Life Sci. 2010; 86:598-603. [PubMed: 19285088]

5. Janecka A, et al. Development of opioid peptide analogs for pain relief. Curr Pharm Des. 2010; 16:1126-1135. [PubMed: 20030621]

6. Vanderah TW. Delta and kappa opioid receptors as suitable drug targets for pain. Clin J Pain. 2010; 26(Suppl 10):S10-15. [PubMed: 20026960]

7. Chaki K, et al. Comparison of the antinociceptive effects of new [D-Arg ${ }^{2}$ ]-dermorphin tetrapeptide analogs and morphine in mice. Pharmacol Biochem Behav. 1988; 31:439-444. [PubMed: 2907624]

8. Ogawa T, et al. Synthesis and structure-activity relationships of an orally available and long-acting analgesic peptide, $\mathrm{N}^{\mathrm{a}}$-amidino-Tyr-D-Arg-Phe-MeßAla-OH (ADAMB). J Med Chem. 2002; 45:5081-5089. [PubMed: 12408719]

9. Mizoguchi H, et al. Dermorphin tetrapeptide analogs as potent and long-lasting analgesics with pharmacological profiles distinct from morphine. Peptides. 2011; 32:421-427. [PubMed: 21126548]

10. Liu HM, et al. Utilization of combined chemical modifications to enhance the blood-brain barrier permeability and pharmacological activity of endomorphin-1. J Pharmacol Exp Ther. 2006; 319:308-316. [PubMed: 16803861]

11. Bryant SD, et al. Dmt and opioid peptides: a potent alliance. Biopolymers Peptide Sci. 2003; 71:86-102.

12. Jutkiewicz EM. The antidepressant-like effects of delta-opioid receptor agonists. Mol Interv. 2006; 6:162-169. [PubMed: 16809477] 
13. Aguila B, et al. In vitro and in vivo pharmacological profile of UFP-512, a novel selective $\delta$-opioid receptor agonist; correlations between desensitization and tolerance. Br J Pharmacol. 2007; 152:1312-1324. [PubMed: 17982482]

14. Vergura R, et al. Anxiolytic- and antidepressant-like activities of H-Dmt-Tic-NH-CH $\left(\mathrm{CH}_{2}-\right.$ $\mathrm{COOH}$ )-Bid (UFP-512), a novel selective delta opioid receptor agonist. Peptides. 2008; 29:93103. [PubMed: 18069089]

15. Mabrouk OS, et al. The novel delta opioid receptor agonist UFP-512 dually modulates motor activity in hemiparkinsonian rats via control of the nigro-thalamic pathway. Neuroscience. 2009; 164:360-369. [PubMed: 19729051]

16. Jinsmaa $Y$, et al. Inhibition of the development of morphine tolerance by a potent dual $\mu$-/ $\delta$-opioid antagonist, H-Dmt-Tic-Lys-NH-CH2-Ph. Pharmacol Biochem Behav. 2008; 90:651-657. [PubMed: 18571706]

17. Marczak ED, et al. Orally administered H-Dmt-Tic-Lys-NH-CH $2-\mathrm{Ph}(\mathrm{MZ}-2)$, a potent $\mu$-/ $\delta$-opioid receptor antagonist, regulates obese-related factors in mice. Eur J Pharmacol. 2009; 616:115-121. [PubMed: 19576206]

18. Largent-Milnes TM, et al. Spinal or systemic TY005, a peptidic opioid agonist/neurokinin 1 antagonist, attenuates pain with reduced tolerance. Br J Pharmacol. 2010; 161:986-1001. [PubMed: 20977451]

19. Hiramatsu M, et al. Long-lasting antinociceptive effects of a novel dynorphin analogue, Tyr-DAla-Phe-Leu-Arg $\Psi\left(\mathrm{CH}_{2} \mathrm{NH}\right)$ Arg- $\mathrm{NH}_{2}$, in mice. Br J Pharmacol. 2001; 132:1948-1956. [PubMed: 11309268]

20. Vats ID, et al. YFa, a chimeric opioid peptide, induces kappa-specific antinociception with no tolerance development during 6 days of chronic treatment. J Neurosci Res. 2008; 86:1599-1607. [PubMed: 18183621]

21. Vats ID, et al. Effect of chronic intra-peritoneally administered chimeric peptide of met-enkephalin and FMRFa-[D-Ala $\left.{ }^{2}\right] \mathrm{YFa}$-on antinociception and opioid receptor regulation. Eur J Pain. 2010; 14:295, e291-299. [PubMed: 19560378]

22. Vats ID, et al. Rationally designed chimeric peptide of Met-enkephalin and FMRFa-[D-Ala ${ }^{2}, p-C l-$ $\mathrm{Phe}^{4} \mathrm{YFa}$ induce multiple opioid receptors mediated antinociception and up-regulate their expression. Eur J Pharmacol. 2010; 638:54-60. [PubMed: 20385120]

23. Brugos B, et al. Stabilized dynorphin derivatives for modulating antinociceptive activity in morphine tolerant rats: effect of different routes of administration. AAPS J. 2004; 6:e36. [PubMed: 15760101]

24. Aldrich JV, et al. Zyklophin, a systemically active selective kappa opioid receptor peptide antagonist with short duration of action. Proc Natl Acad Sci USA. 2009; 106:18396-18401. [PubMed: 19841255]

25. Witt KA, Davis TP. CNS drug delivery: opioid peptides and the blood-brain barrier. AAPS J. 2006; 8:E76-88. [PubMed: 16584136]

26. Polt R, et al. Glycosylated neuropeptides: a new vista for neuropsychopharmacology? Med Res Rev. 2005; 25:557-585. [PubMed: 16075406]

27. Lowery JJ, et al. In vivo characterization of MMP-2200, a mixed $\mu / \delta$ opioid agonist, in mice. J Pharmacol Exp Ther. 2011; 336:767-778. [PubMed: 21118955]

28. Do Carmo GP, et al. Behavioral pharmacology of the $\mu / \delta$ opioid glycopeptide MMP2200 in rhesus monkeys. J Pharmacol Exp Ther. 2008; 326:939-948. [PubMed: 18511649]

29. Witt KA, et al. Pharmacodynamic and pharmacokinetic characterization of poly(ethylene glycol) conjugation to met-enkephalin analog [D-Pen ${ }^{2}$, D-Pen $\left.{ }^{5}\right]$-enkephalin (DPDPE). J Pharmacol Exp Ther. 2001; 298:848-856. [PubMed: 11454951]

30. Huber JD, et al. Conjugation of low molecular weight poly(ethylene glycol) to biphalin enhances antinociceptive profile. J Pharm Sci. 2003; 92:1377-1385. [PubMed: 12820142]

31. Bedini A, et al. Peripheral antinociceptive effects of the cyclic endomorphin-1 analog c[YpwFG] in a mouse visceral pain model. Peptides. 2010; 31:2135-2140. [PubMed: 20713109]

32. Ross NC, et al. Synthesis of CJ-15,208, a novel $\kappa$-opioid receptor antagonist. Tetrahedron Lett. 2010; 51:5020-5023. [PubMed: 22865937] 
33. Vanderah TW, et al. FE200041 (D-Phe-D-Phe-D-Nle-D-Arg- $\mathrm{NH}_{2}$ ): A peripheral efficacious $\kappa$ opioid agonist with unprecedented selectivity. J Pharmacol Exp Ther. 2004; 310:326-333. [PubMed: 14993260]

34. Vanderah TW, et al. Novel D-amino acid tetrapeptides produce potent antinociception by selectively acting at peripheral $\kappa$-opioid receptors. Eur J Pharmacol. 2008; 583:62-72. [PubMed: 18282565]

35. Wallace MS, et al. A Phase II, multicenter, randomized, double-blind, placebo-controlled crossover study of CJC-1008--a long-acting, parenteral opioid analgesic--in the treatment of postherpetic neuralgia. J Opioid Manag. 2006; 2:167-173. [PubMed: 17319450]

36. Arendt-Nielsen L, et al. Analgesic efficacy of peripheral $\kappa$-opioid receptor agonist CR665 compared to oxycodone in a multi-modal, multi-tissue experimental human pain model: selective effect on visceral pain. Anesthesiology. 2009; 111:616-624. [PubMed: 19672186]

37. Smith JP, et al. Opioid growth factor improves clinical benefit and survival in patients with advanced pancreatic cancer. Open Access J Clin Trials. 2010; 2010:37-48. [PubMed: 20890374]

38. Fink DJ, et al. Gene therapy for pain: results of a Phase I clinical trial. Ann Neurology. 2011 in press. 10.1002/1001n1001.22446

39. Marx M. Watching peptide drugs grow up. Chem Eng News. 2005; 83:17-24.

40. Van Dorpe S, et al. Analytical characterization and comparison of the blood-brain barrier permeability of eight opioid peptides. Peptides. 2010; 31:1390-1399. [PubMed: 20347901] 
Dermorphin analogs:

Tyr-D-Ala-Phe-Gly-Tyr-Pro-SerNH ${ }_{2}$ Dermorphin

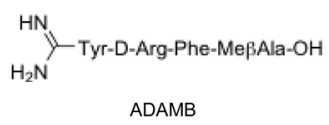

Dmt-D-Arg-Phe-Lys- $\mathrm{NH}_{2}$

Dmt-DALDA

Dmt-D-Arg-Phe-Lys-NH- $\mathrm{CH}_{2}$

Tyr-Tic $\Psi\left[\mathrm{CH}_{2}-\mathrm{NH}\right]$ Cha-Phe-NH- $\mathrm{CH}_{2}$

Dmt-DALDA-CH ${ }_{2}-\mathrm{NH}$ (TICP $\left.\Psi\right)$

Endomorphin analogs:

Tyr-Pro-Trp-PheNH

Endomorphin-1

R-Tyr-D-Ala-Trp-Phe(X)NH

$\mathrm{R}=$ guanidino or $\mathrm{H}$

$\mathrm{X}=p$ - $\mathrm{Cl}$ or $\mathrm{H}$

$\mathrm{H}_{2} \mathrm{~N}-$ Tyr-D-Pro-Gly-Trp-Phe(p-Cl)-NH

Dmt-Tic derivatives:
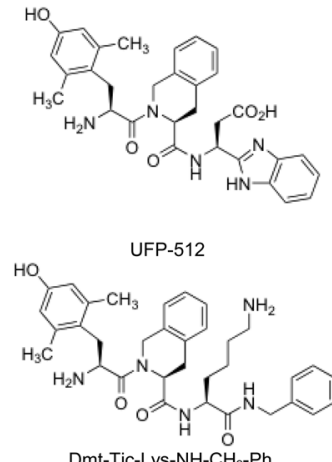

Dmt-Tic-Lys-NH-CH $-\mathrm{Ph}$

$\mathrm{MZ}-2$

Opioid/neurokinin ligand:

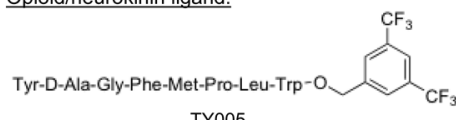

Dynorphin analogs and related peptides:

RTyr-Gly-Gly-Phe-Leu-Arg-Arg-lle-Arg-Pro-Lys-Leu-Lys-X

\begin{tabular}{lll}
\multicolumn{1}{c}{ Dyn A-(1-13) } & $\mathrm{R}$ & $\mathrm{X}$ \\
[NMeTyr']Dyn A-(1-13) & $\mathrm{H}$ & $\mathrm{OH}$ \\
" " amide & $\mathrm{CH}_{3}$ & $\mathrm{OH}$ \\
& $\mathrm{CH}_{3}$ & $\mathrm{NH}_{2}$
\end{tabular}

NMeTyr-Gly-Gly-Phe-Leu-Arg-NMeArg-D-Leu-NHEt

E-2078

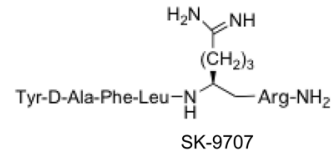

Tyr-R-Gly-Phe(p-X)-Met-Lys-Lys-Lys-Phe-Met-Arg-Phe-NH

\begin{tabular}{lll} 
& \multicolumn{1}{c}{$\mathrm{R}$} & $\mathrm{X}$ \\
\cline { 2 - 3 } YFa & Gly & $\mathrm{H}$ \\
{$\left[\mathrm{D}-\mathrm{Ala}{ }^{2}\right] \mathrm{YFa}$} & $\mathrm{D}-\mathrm{Ala}$ & $\mathrm{H}$ \\
{$\left[\mathrm{D}-\mathrm{Ala}{ }^{2}, \mathrm{Phe}\left(p-\mathrm{Cl}^{4}\right] \mathrm{YFa}\right.$} & D-Ala & $\mathrm{Cl}$
\end{tabular}

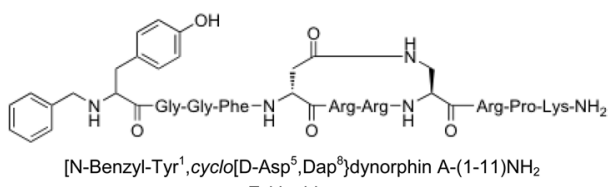
Zyklophin

Glycosylated and pegylated peptides:

Tyr-Gly-Gly-Phe-Leu

Leu-enkephalin

Tyr-D-Thr-Gly-Phe-Leu-Ser-NH

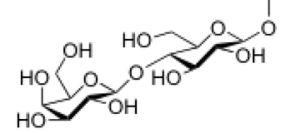

[D-Thr'] ]enkephalin-Ser $(\beta \text {-D-lactose })^{6}$ amide MMP-2200

PEG $(2 \mathrm{kDa})-\left(\mathrm{CH}_{2}\right)_{2} \prod_{\mathrm{O}}$ Tyr-D-Pen-Gly-Phe-D-Pen

PEG-DPDPE

PEG (2kDa)-Tyr-D-Ala-Gly-Phe-NH

PEG (2kDa)-Tyr-D-Ala-Gly-Phe-NH Di-PEG-biphalin

Drug Discov Today Technol. Author manuscript; available in PMC 2013 April 01. 
Novel opioid peptides:<smiles>O=C(CNC(=O)[C@H](Cc1ccccc1)NC(=O)[C@H](Cc1c[nH]c2ccccc12)NC(=O)C1CCCN1C(=O)[C@H](Cc1ccc(O)cc1)NC(=O)Cc1c[nH]c2ccccc12)NC(Cc1ccccc1)Cc1ccccc1</smiles>

D-Phe-D-Phe-D-Nle-D-Arg-NHR

FE200041

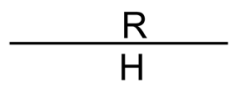

FE2006665

(CR665)

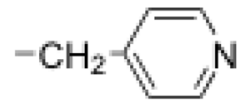

\section{c[YpwFG]}

Figure 1.

Structures of opioid peptide analogs exhibiting systemic activity compared to the endogenous opioid peptides. Structures of CJC-1008 and CR845 were not reported.

Abbreviations used are: Cha, cyclohexylalanine; Dap, 2,3-diaminoproprionic acid; Dmt, 2', 6'-dimethyltyrosine; DPDPE, cyclo[D-Pen ${ }^{2}, \mathrm{D}-\mathrm{Pen}^{5}$ ]enkephalin; Pen, penicillamine; Tic, 1,2,3,4-tetrahydroisoquinoline-3-carboxylic acid; PEG, poly(ethylene glycol). $\Psi\left[\mathrm{CH}_{2} \mathrm{NH}\right]$ denotes a reduced amide bond. 
Table 1

Potential therapeutic applications currently being explored for opioid peptides targeting different opioid receptors. $^{a}$

\begin{tabular}{|c|c|c|}
\hline Opioid receptor activity & Therapeutic application & Example and reference \\
\hline MOR agonist $b$ & Analgesia & Dmt-DALDA plus several others - see tex \\
\hline DOR agonist & Analgesia; anti-depressant and anxiolytic activity & UFP-512 [13,15] \\
\hline $\begin{array}{l}\text { DOR antagonist } \\
\text { Also in combination with MOR } \\
\text { agonist activity }\end{array}$ & Reduction in MOR agonist-induced tolerance & $\begin{array}{l}\text { MZ-2 [16] } \\
\text { Dmt-DALDA-CH} 2 \mathrm{NH}(\mathrm{TICP} \Psi) \text { [4] }\end{array}$ \\
\hline KOR agonist & $\begin{array}{l}\text { Peripherally restricted analgesics, especially for } \\
\text { visceral and inflammatory pain }\end{array}$ & CR665 $[34,36]$ and CR845 \\
\hline KOR antagonist & $\begin{array}{l}\text { Treatment for drug abuse (stress-induced } \\
\text { reinstatement) }\end{array}$ & Zyklophin [24] \\
\hline
\end{tabular}

${ }^{a}$ See ref. [6] for a review of DOR and KOR as drug targets

${ }^{b}$ Also in combination with activity at other receptors, e.g. DOR or KOR agonist activity. 


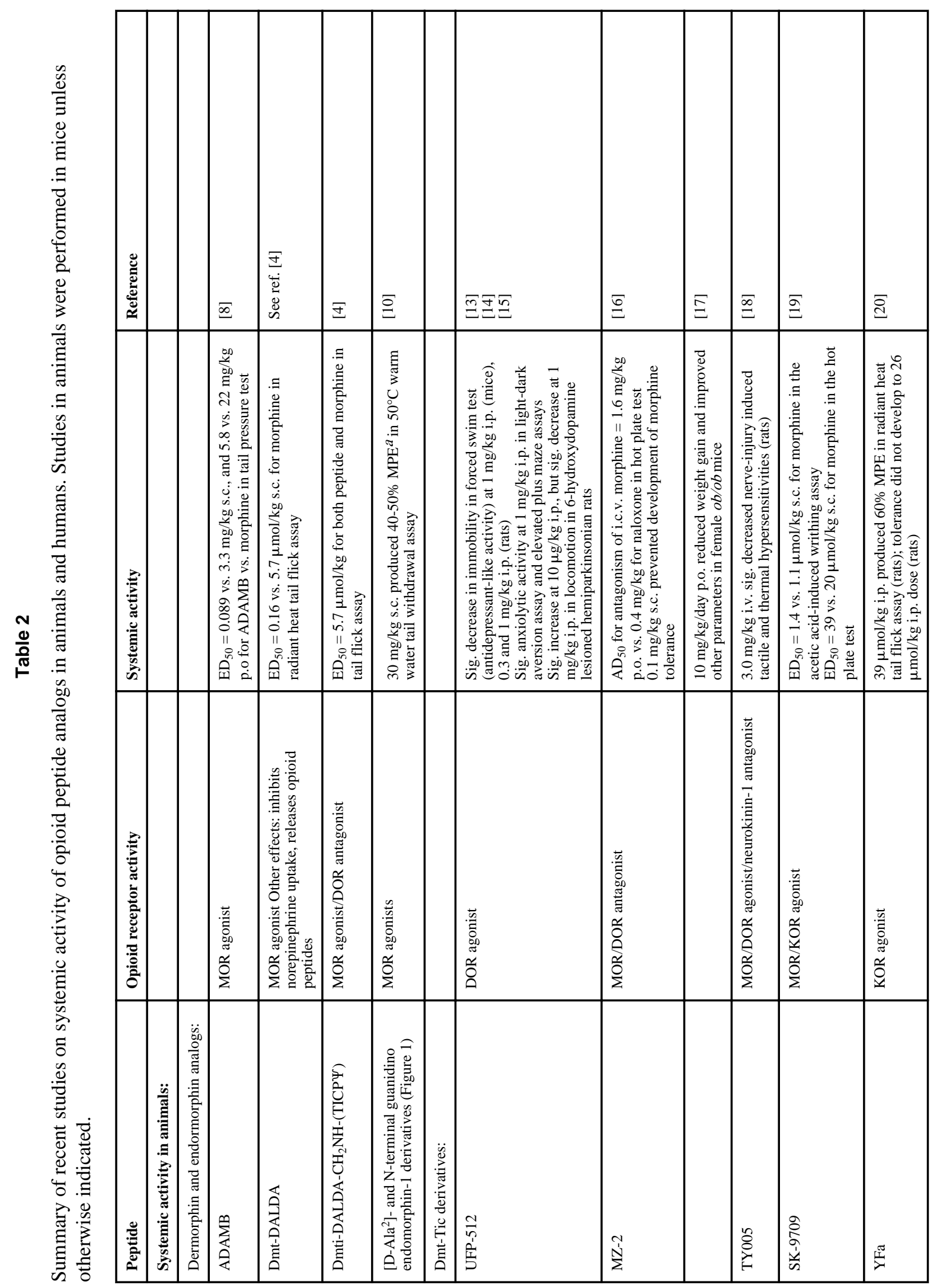




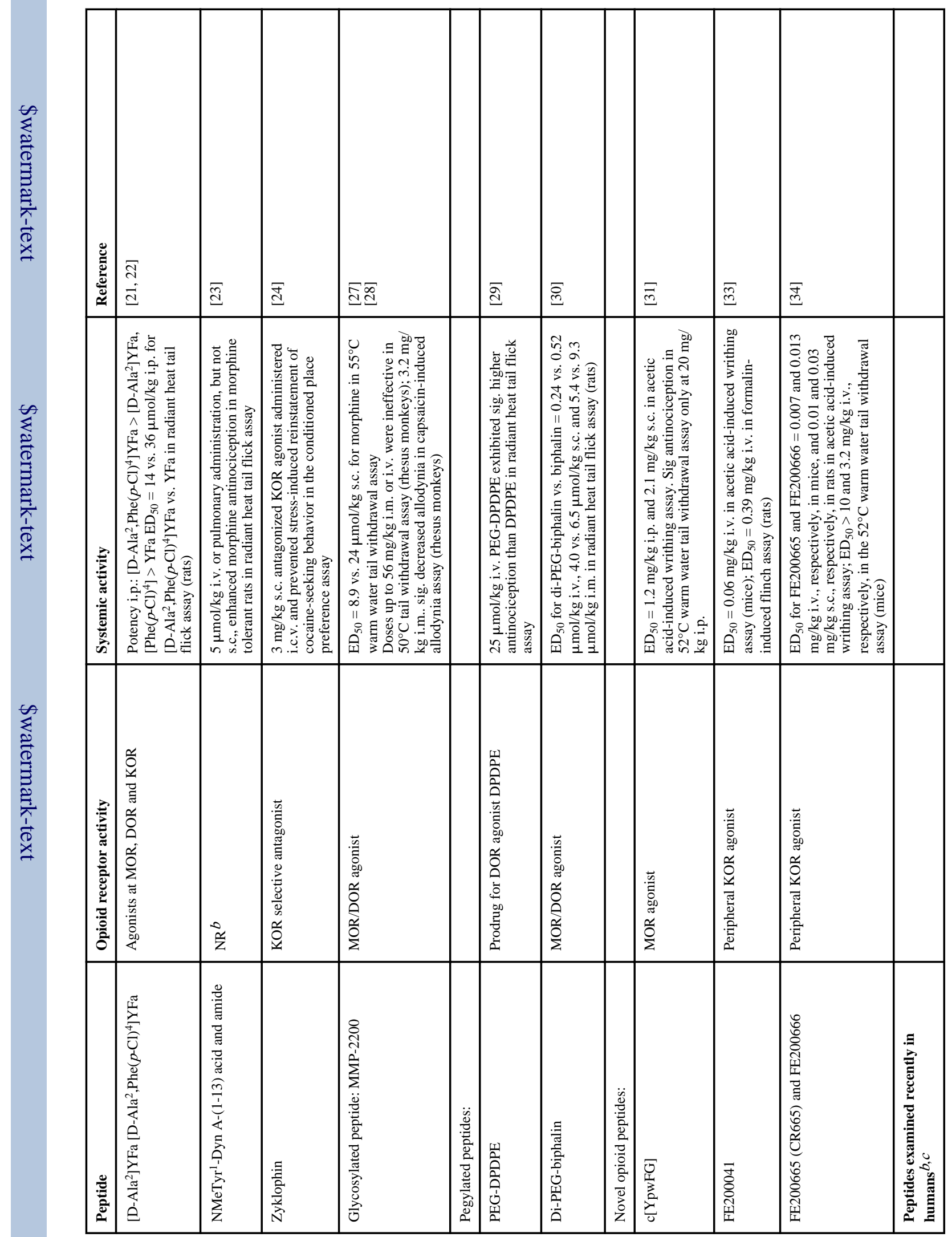




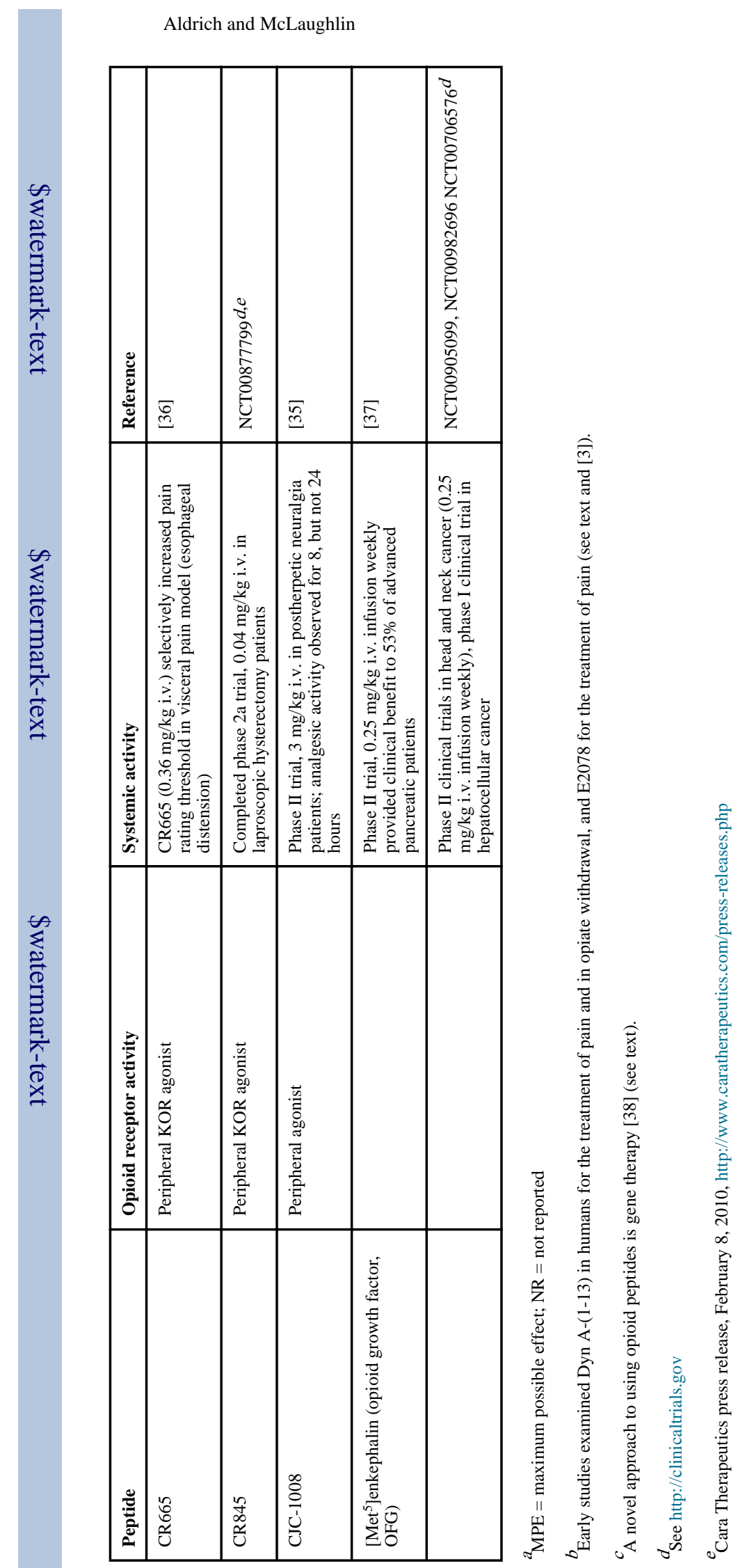

Drug Discov Today Technol. Author manuscript; available in PMC 2013 April 01. 